\title{
The knowledge citizen as the influencer and the influenced - Part 2
}

\author{
Melanie Sutton \\ msutton@iqgroup.net
}

\section{Introduction}

You don't have to be a person of influence to be influential. In fact, the most influential people in my life are probably not even aware of the things they've taught me (Scott Adams).

In Part 1 of this article, the phenomenon of influence was introduced as a characteristic of the archetype of a knowledge citizen, and two principles of influence, namely reciprocation and commitment and consistency, according to the social psychologist Robert Cialdini, were presented.

In Part 2 of this article, the remaining four principles of influence, namely social proof, liking, authority and scarcity, are explored. The discussion offers the knowledge citizen insight into behaviour that often contributes to our effectiveness, both as influencers and recipients of influential behaviour.

We further add to the archetype by exploring what it means to persuade and the steps one needs to use persuasion effectively.

\section{Influence - science and practice}

Research by social psychologist, Robert Cialdini, reveals that there are six basic principles that govern how one person might influence another. These include reciprocation, consistency and commitment, social proof, authority, liking and scarcity. We elaborate on the remaining four of the six principles and highlight some of their applications in the archetype of the knowledge citizen.

\section{Social proof}

The principle of social proof states that people look at what other people are doing in order to decide what to believe or how to act in a situation. Powerful imitative effects have been found among children and adults and in diverse activities such as purchasing, making a donation or remission from a health problem. The principle of social proof can be used to stimulate a person's compliance with a request by informing the person that many other individuals are or have been complying with it.

Social proof is influential under two conditions:

- Uncertainty - When people are unsure, when the situation is ambiguous, they are more likely to attend to the actions of others and to accept those actions as correct.

- Similarity - People are more inclined to follow the lead of similar others.

To reduce our susceptibility to faulty social proof, we must be sensitive to clearly counterfeit 
evidence of what similar others are doing and recognizing that the actions of similar others should not form the basis of our decisions.

The examples given in part 1 of this article highlight two individuals who are influential through social proof, namely Lance Armstrong and Lorena Ochoa. Knowledge citizens can use social proof to influence their colleagues by demonstrating desired knowledge citizenship behaviour such as knowledge sharing.

\section{Liking}

People prefer to say 'yes' to individuals they know and like and often individuals will increase their effectiveness by emphasizing several factors that increase their overall attractiveness and likeability.

Overall liking is influenced by several factors:

- Physical attractiveness - This appears to engender a halo effect that extends to favourable impressions of other traits such as talent, kindness and intelligence. Hence, attractive people are more persuasive in terms of getting what they request and in changing others' attitudes.

- Similarity influences liking, that is we like people who are like us and we are more willing to say 'yes' to their requests, often in an unthinking manner.

- Praise and compliments generally enhance liking and thus compliance.

- Increased familiarity through repeated contact with a person or thing normally facilitates liking, especially if the contact takes place under positive rather than negative circumstances

- Association - By connecting themselves or products to positive things, companies and people seek to share in the positivity through the process of association.

When recognizing that we like a requester inordinately well under certain circumstances, we should separate ourselves from the social interaction and the requester from his or her offer and make the compliance decision solely on the merits of the offer.

This principle is by far the most subjective of all but the most accessible in terms of execution. By being aware of these factors, knowledge citizens can use this principle to positively influence their environment.

\section{Authority}

The tendency to obey legitimate authorities stems from systematic socialization practices designed to instill in members of society the perception that such obedience constitutes correct conduct. Authorities are often seen as individuals who possess high levels of knowledge, wisdom and power and often deference to authorities can occur in a mindless fashion as a kind of decision-making shortcut.

When reacting to authority in automatic fashion, there is a tendency to do so in response to mere symbols of authority rather than substance, that is titles, clothing and automobiles.

To counter being adversely influenced by the principle of authority, we should ask ourselves two questions: Is the authority truly an expert and how truthful do we expect this expert to be? The first question draws our attention away from symbols and towards evidence for authority status and the second advises us to consider the person's trustworthiness. 
- Things that are difficult to attain are typically more valuable and the availability of an item or experience can serve as a shortcut cue to its quality.

- As things become less accessible, we lose our freedom and, psychologically, we respond to the loss of freedom by wanting to have them more than before.

Scarcity is most likely to be true under a number of conditions:

- Scarce items are heightened in value when they are newly scarce .

- We value items that have become recently restricted more than those that were restricted all along.

- We are most attracted to scarce resources when we compete with others for them.

Scarcity is emotionally charged and, to counteract the pressure, one should assess the merits of the opportunity in terms of why we want the item or service.

\section{Positioning persuasion}

Whereas influence focuses more on the long term and involve entrenched habits that require people to change, persuasion is more short term and focuses on getting a person's honest verbal agreement or commitment.

To persuade, one must prevail upon a person to do something, either by advising or urging. Persuasion attempts to win the heart and minds of a target group and a change in attitude means persuasion has occurred. To be persuasive requires a combination of verbal and nonverbal communication.

Jay Congor, a professor of organizational behaviour at University of Southern California's Marshall School of Business, asserts that persuasion is often misunderstood and underutilized. Instead of being a positive source of influence, it is widely perceived as a skill reserved for selling products and closing deals, another form of manipulation that honest people would not endeavour to use. However, exercised constructively, effective persuasion becomes a negotiating and learning process through which a persuader leads colleagues to a problem's shared solution.

Persuasion does indeed involve moving people to a position they don't currently hold, but not by begging or cajoling. Instead, it involves careful preparation, the proper framing of arguments, the presentation of vivid supporting evidence, and the effort to find the correct emotional match with your audience.

\section{Effective persuasion}

Persuasion is a learning and negotiating process that involves phases of discovery, preparation and dialogue. Effective persuaders consider their positions from every angle and use dialogue to learn more about their audience's opinions, concerns and perspectives.

During the process, dialogue continues to be a form of learning, but it is also the beginning of the negotiation stage. A persuader invites people to discuss, even debate, the merits of a position, and then offers honest feedback and suggests alternative solutions.

Effective persuasion is about testing and revising ideas in concert with others' concerns and needs. In fact, the best persuaders not only listen to others but also incorporate their perspectives into a shared solution.

The most effective persuaders share a common trait, namely they are open-minded, and enter the persuasion process prepared to adjust their viewpoints and incorporate others' ideas, which in itself is highly persuasive. 
Effective persuaders use four distinct and essential steps when engaging with others:

- Establish credibility

- Frame goals in a way that identifies common ground with those they intend to persuade

- Reinforce positions using vivid language and compelling evidence

- Connect emotionally with their audience.

\section{Conclusion}

The six principles of influence as presented by Cialdini and usefulness of persuasion submitted by Congor identify powerful features to add to the archetype of a knowledge citizen. By using these techniques, the knowledge citizen has the opportunity to change, if not the world, at least his or her own environment.

\section{Consulted}

Cialdini, R.B. 2001. Influence - science and practice. Boston. Allyn and Bacon.

Cialdini, R.B. and Goldstein, J. 2001 The science and practice of persuasion. [Online]. Available WWW http://www.influenceatwork.com/Media/RBC/CornellHotelRestAdminQrtly.pdf

Congor, J. 1998. The necessary art of persuasion. [Online]. Available WWW http://harvardbusinessonline.hbsp.harvard.edu/hbsp/hbr/articles/article.jsp? $\underline{\text { articleID }=98304 \& \mathrm{ml} \text { action }=\text { get-article\&print }=\text { true \&ml_issueid }=\text { null }}$

Rodger, G. 2006. On knowledge and influence. [Online]. Available http://www.longwoods.com/product.php?printable=Y\&productid $=18595 \&$ cat $=461$

\section{About the author}

Melanie Sutton (BA, Postgraduate Diploma in Information Management) is a Senior Principal Consultant in the Enterprise Content Management Discipline and a member of Intellectual Property Forum at The IQ Business Group, South Africa.

\section{Disclaimer}

Articles published in SAJIM are the opinions of the authors and do not necessarily reflect the opinion of the Editor, Board, Publisher, Webmaster or the Rand Afrikaans University. The user hereby waives any claim he/she/they may have or acquire against the publisher, its suppliers, licensees and sub licensees and indemnifies all said persons from any claims, lawsuits, proceedings, costs, special, incidental, consequential or indirect damages, including damages for loss of profits, loss of business or downtime arising out of or relating to the user's use of the Website. 